\title{
A memoria em Los informantes, de Juan Gabriel Vásquez
}

\section{The memory in Los informantes, by Juan Gabriel Vásquez}

\author{
Diogo De Hollanda Cavalcanti ${ }^{1}$ \\ Recibido: 10 de Marzo 2013. Aprobado: 23 de Abril de 2013
}

\begin{abstract}
Resumo
De que maneira a distância do país de origem pode influenciar a memória de autores em condição de deslocamento? Guiada por esta pergunta, a presente comunicação propõe uma análise do romance Los informantes (2004), do colombiano radicado na Espanha Juan Gabriel Vásquez. Inspirado em um episódio ainda pouco conhecido da história latino-americana - a criação de listas negras e campos de concentração para imigrantes dos países do Eixo durante a Segunda Guerra Mundial -, o romance é exemplo de uma memória questionadora, capaz de colocar em xeque a "história oficial" e desvelar as dissonâncias da suposta harmonia nacional.
\end{abstract}

Palabras clave: Los informantes; Juan Gabriel Vásquez; Novela colombiana; Memoria

\begin{abstract}
How does the distance of the country of origin may influence the memory of authors in displacement condition? Guided by this question, this Communication proposes an analysis of the novel Los informantes (2004), the Colombian who lives in Spain Juan Gabriel Vásquez. Inspired by a little known episode in the history of Latin America - the blacklisting and concentration camps for immigrants from the countries of the Axis powers during the Second World War - the novel is an example of a questioning memory, able to checkmate the "official story" and reveal the dissonances of the alleged national harmony.
\end{abstract}

Keywords: Los informantes; Juan Gabriel Vásquez; Colombian novel; Memory.

\section{Deslocamentos na literatura hispano-americana}

Exílios políticos, missões diplomáticas, peregrinações culturais. Independentemente do propósito, o deslocamento dos escritores é um dos elementos de maior permanência na produção literária hispano-americana. Das crônicas do período colonial à literatura contemporânea, um extenso conjunto de obras, entre as mais representativas da América Latina, nasce com os autores fora de seus países de origem. Um inventário despretensioso, de ambições meramente ilustrativas, poderia começar no século XVII, com o Inca Garcilaso de la Vega, e chegar aos dias atuais passando por poetas neoclássicos, escritores

\footnotetext{
${ }^{1}$ Doutorando do Programa de Pós-Graduação em Letras Neolatinas da Universidade Federal do Rio de Janeiro.
} 
românticos, grandes nomes do modernismo, expoentes da vanguarda e os principais representantes do chamado boom da literatura hispano-americana. Hoje, a continuidade do fenômeno é ilustrada pelos eventos e coletâneas que procuram oferecer uma amostra da literatura produzida pelas novas gerações. Dos 16 hispano-americanos incluídos na antologia Los mejores narradores jóvenes en español da revista inglesa Granta (2010), oito estão radicados fora da América Latina ${ }^{2}$ - divididos entre Estados Unidos (onde geralmente seguem carreira acadêmica) e Espanha (onde veem mais chances de ser editados). Da mesma forma, dos 39 escritores com menos de 39 anos considerados promissores no festival Bogotá 39, realizado em 2007, quase metade (precisamente 17) vive fora de seus países $^{3}$.

Nesta longa tradição, salta aos olhos a recorrência com que, guiados pela memória, os autores abordam temas ligados à terra em que nasceram, muitas vezes transformada no cenário único de seus escritos. O exemplo do Inca Garcilaso de la Vega - que escreveu Los comentarios reales (1606) 45 anos depois de trocar o Peru pela Espanha - serve, mais uma vez, apenas para capitanear uma lista volumosa que inclui a maior parte dos escritores latino-americanos que algum dia se estabeleceram fora de seus países. Muitos afirmam que a distância proporcionou-lhes uma visão mais clara da realidade que deixaram. Em uma conferência pronunciada em $2005^{4}$, Mario Vargas Llosa, por exemplo, contou ter descoberto a América Latina apenas quando viveu em Paris durante os anos 1960. "Não se pode entender a América Latina sem sair dela e observá-la com os olhos e, também, com os mitos e estereótipos que se elaboram sobre ela no estrangeiro", afirmou o escritor peruano. Autores surgidos nos últimos 20 anos - que experimentam o deslocamento de maneira bem diversa da geração do boom - também destacam esse possível efeito de nitidez que o olhar à distância propicia.

Mas há, de fato, a perspectiva de uma visão mais lúcida para quem, de longe, lança os olhos sobre sua pátria? De que maneira a distância do país de origem pode influenciar a memória de um autor que se dispõe a escrever sobre ele?

\footnotetext{
${ }^{2}$ Em julho de 2011.

${ }^{3}$ Idem.

${ }^{4}$ Apud VARGAS LLOSA, MARIO. Sables y utopías: visiones de América Latina. Buenos Aires: Aguilar, Altea, Taurus, Alfaguara, 2009, p.365.
} 


\section{Memórias deslocadas}

Uma interessante possibilidade de resposta está no livro Memorias migrantes: testimonios y ensayos sobre la diáspora uruguaya (2003), do acadêmico uruguaio Abril Trigo. Baseandose no trabalho etnográfico que realizou numa comunidade de uruguaios em Fitchburg, Massachusetts (EUA), Trigo afirma que, ao mudar de país, os sujeitos sofrem uma fratura identitária que os leva a empreender, de maneira quase imperceptível, um movimento de resgate e reciclagem de memórias culturais até então soterradas na memória histórica e no imaginário social da nação deixada. O principal efeito deste processo, ou pelo menos o mais fecundo, é o surgimento de novas formas de olhar a comunidade nacional - formas alternativas que conseguem se desvencilhar da ação homogeneizadora da memória histórica, incorporar diferenças antes esmagadas e colocar em xeque os pilares do imaginário social.

Trigo recorre ao conceito de interpelação ideológica formulado por Althusser $(1971 ; 1972)$ para explicar o funcionamento do imaginário social. Assim como a ideologia, o imaginário social é sustentado pelo prazer que provoca no indivíduo - o prazer do pertencimento, o prazer que une os membros de uma comunidade em torno de uma fantasia coletiva. Discernir o que há de falacioso nos símbolos, mitos e valores sobre os quais repousa a ideia da nacionalidade é geralmente mais difícil para o sujeito que permanece sempre no mesmo país, nutrindo sua identidade dos atributos que lhe renovam, a cada dia, a convicção de integrar uma coletividade. Da mesma forma, enxergar e denunciar as imposturas da memória histórica - ou seja, da memória transmitida pela "história oficial" - tende a ser mais árduo para quem jamais se ausenta, física ou imaginariamente, da terra em que nasceu. Produzida pelos aparelhos ideológicos do Estado e guiada primordialmente por objetivos nacionalistas (TRIGO, 2003, p.98), a memória história se dirige, acima de tudo, aos indivíduos de uma nação. E, para isso, se vale de um aparato discursivo que abrange desde eventos, como aniversários, comemorações cívicas e festivais, a lugares como monumentos, museus e santuários 5 .

\footnotetext{
${ }^{5}$ Sobre os lugares da memória histórica, ver NORA, Pierre (ed). Les lieux de mémoire. Paris: Gallimard, 1984.
} 
Em sua dupla condição psicológica e social, a memória não é a mera repetição e recuperação das marcas do ontem, mas a construção de um passado posto a serviço de um projeto de futuro a partir das circunstâncias do presente (TRIGO, 2003, p.93). Longe do país de origem, com novas exigências imaginárias, os indivíduos deslocados reformulam suas lembranças vivenciando um processo de "esquecimento criativo" que os distancia, cada vez mais, do imaginário social e da memória histórica. Trigo menciona, por exemplo, que os migrantes de Fitchburg, com o passar dos anos, praticamente não celebram mais as festas nacionais do Uruguai e raramente invocam seus símbolos pátrios. A quebra desses vínculos anteriormente prazerosos deflagra uma crise identitária que provoca, entre outras consequências, a irrupção da chamada imaginação radical, força questionadora com a qual o indivíduo, que o imaginário social quisera domesticar e reduzir a mero sujeito-súdito, afirma-se como sujeito-agente e, através de práticas antagônicas, no questionamento tenaz e persistente do imaginário social, conquista a autonomia, tornando-se mais apto a desconstruir a "história oficial" e sugerir novas formas de pensar o nacional (idem, p.80$85)$.

Por indevidas que sejam as generalizações, é impossível não identificar coincidências entre o processo descrito por Trigo e o trabalho desenvolvido por inúmeros escritores em deslocamento, que capitanearam nos últimos anos algumas das empreitadas mais arrojadas de retorno literário ao passado da América Latina. Analisando um amplo corpus de hispano-americanos, Fernando Aínsa (2005) destaca o expressivo conjunto de narrativas em que os autores reconstroem à distância, com olhar crítico e desmistificador, o país ou a cidade em que nasceram. Aínsa cita Fernando Vallejo com Bogotá (escrevendo do México), Juan Villoro com o México (escrevendo de Barcelona), Abilio Estévez com Havana (também de Barcelona), Carlos Franz com o Chile (escrevendo de Madri), entre outros tantos que mostram que "um espaço nacional construído fora das fronteiras não só é possível, como recomendável”.

Chamam atenção os longos períodos que, após a mudança, vários tardam para escrever sobre a pátria em que nasceram. Para Juan Gabriel Vásquez, foram oito anos entre sua saída da Colômbia e a publicação de Los informantes (2004), seu primeiro livro sobre o país. 
Estaria aí o esquecimento criativo mencionado por Trigo? "Uma das consequências de emigrar é que, depois de um tempo, desaparece a ilusão da compreensão: aquela ilusão apenas humana de que você entende o lugar de onde vem”, comentou Vásquez (2009, p.187), em breve ensaio sobre a condição de escritor deslocado.

Outros autores relatam situações parecidas, como o hispano-argentino Andrés Neuman, que se mudou para a Espanha em 1991 e somente seis anos depois conseguiu escrever sobre sua cidade natal, Buenos Aires. "Na época”, contou ele num artigo, "entre meu lugar de origem e mim havia a distância justa: conhecia-o bem, mas tinha começado a esquecê-lo e, portanto, a ser capaz de imaginá-lo. Sem memória profunda, não há ficção que valha” (CORRAL, 2004, p.43).

Frequentemente, é o próprio percurso da memória, com suas glórias e abismos, suas veredas e encruzilhadas, que captura os escritores e se transforma em tema central de suas obras. Assim como Neuman em Bariloche (1998) - em que o quebra-cabeça do protagonista representa o jogo de forças entre lembranças e esquecimento -, Juan Gabriel Vásquez faz, em Los informantes, uma intensa e percuciente reflexão sobre a memória. Ao longo da narrativa, marcada por uma visão extremamente crítica da Colômbia, encontramse não apenas grandes questões para a filosofia de todos os tempos, como alguns dos principais dilemas com que a América Latina se defronta na hora de trazer à tona o passado de horrores cometidos no século XX. Em países marcados por traumas, o que deve ser lembrado e o que pode ser esquecido? Como arrostar o futuro com o peso asfixiante do

passado? É possível perdoar? Até que ponto são confiáveis as reconstituições feitas pelas testemunhas?

\section{Deslocamento e memória em Los informantes}

O romance resgata um episódio ainda pouco conhecido da histórica latino-americana: a criação de listas negras e campos de concentração para imigrantes dos países do Eixo 
durante a Segunda Guerra Mundial. Na Colômbia, assim como no Brasil ${ }^{6}$, a mudança de posicionamento do governo durante o conflito - com a decisão de apoiar os Aliados, liderados pelos Estados Unidos - deu início a um período de perseguição a japoneses, italianos e alemães. Acolhidos nas décadas anteriores, imigrantes dessas nacionalidades passaram a ser duramente hostilizados, e castigados com expropriação de bens e confinamento diante de qualquer suspeita, comprovada ou não, de que tivessem envolvimento ou afinidade ideológica com o nazismo. Famílias foram destruídas, patrimônios dilacerados e inúmeros suicídios foram cometidos por pessoas incluídas nas chamadas listas negras do Departamento de Estado Norte-Americano.

O interesse maior do romance, contudo, mais do que evocar esses acontecimentos, é mostrar como eles continuam vivos e o quão difícil - embora necessária - é a tarefa de rememorá-los. O personagem narrador, Gabriel Santoro, é um jornalista bogotano que, entre o fim dos anos 1980 e a primeira metade da década de 1990, realiza dois esforços consecutivos de reconstrução memorial do período: o primeiro, a biografia da judia alemã Sara Guterman, amiga de seu pai que chega à Colômbia em 1938 escapando do nazismo com a família; e o segundo, desempenhado ao longo do livro, uma espécie de ampliação e revisão do relato anterior, na qual o pai de Gabriel, que havia escondido um segredo por toda a vida, passa a ter participação ativa nos eventos narrados.

Gabriel pai e Sara Guterman são as pessoas mais próximas do jornalista - sua atual família - e representam, emblematicamente, os dois extremos da tensão entre lembrar e esquecer que marca países com traumas não superados. Renomado professor de retórica, repleto de condecorações dadas pelo governo, Gabriel carrega em silêncio a culpa de ter traído Konrad, pai de seu amigo Enrique, delatando-o, injustamente, por manter relações com nazistas. Sem jamais referir-se àqueles tempos, cuidando até mesmo de afastar vestígios da juventude em seu apartamento, Gabriel apregoa o esquecimento coletivo, mas tem a impossibilidade de esquecer gravada no próprio corpo, nos quatro dedos da mão arrancados

\footnotetext{
${ }^{6}$ No Brasil, foram criados 11 campos de concentração e chegou a ser proibido falar o idioma dos três países do bloco (FÁVERI, 2005).
} 
a faca por Enrique em represália pelo suicídio do pai. Sara, por sua vez, empenha-se em preservar a memória desde a adolescência, quando procurava reconstituir os dias de sua chegada à Colômbia com perguntas aos familiares. Guarda documentos em diferentes pastas, organizadas por cores e outras distinções. Ao notar que Gabriel faria de tudo para esquecer os episódios que levaram à morte de Konrad, assume para si a responsabilidade de lembrá-los. Seus anseios de rememoração, no entanto, são tolhidos pelos próprios filhos, que a impedem de contar aos netos os episódios testemunhados. "Eu era e talvez ainda seja essa coisa tão terrível: uma memória que está proibida de dizer que se lembra” (VÁSQUEZ, 2004, p.118).

A Colômbia recriada no livro pende inegavelmente para o esquecimento. Apontadas por Paul Ricoeur (2007) como uma das práticas mais frequentes de manipulação da memória, as comemorações nacionais - que muitas vezes não passam da evocação coletiva das glórias pátrias - proliferam a ponto de constituir uma tradição (VÁSQUEZ, 2004, p.25). Os arquivos públicos são tratados com desleixo, e importantes documentos históricos, como as cartas familiares buscadas por Enrique, acabam se transformando em lixo. Neste ambiente avesso a recordações - em que a memória, tantas vezes, é apenas uma mercadoria descartável $^{7}$-, não é de se admirar que Gabriel pai figure quase como um herói, objeto de culto da elite e cidadão modelo para o poder. Erigida sobre um discurso oco - em que o manejo exímio das palavras contrasta com o veemente desprezo pelos significados -, sua glória se sustenta, necessariamente, no desconhecimento de sua vida pregressa. Quando o filho publica a biografia de Sara, remexendo no passado que o pai gostaria de ver sepultado, sua reação beira o desespero. “A memória não é pública”, esbraveja (idem, p.74).

No antagonismo entre pai e filho, emerge a tensão entre oralidade e escrita que marca todo o romance. Mestre do discurso falado, Gabriel pai tem como material "as palavras pronunciadas e lidas, mas nunca escritas por sua mão" (VÁSQUEZ, 2004, p.24). Já Gabriel filho, jornalista e escritor, acredita na capacidade ordenadora das palavras redigidas (idem, p.34). Uma primeira

\footnotetext{
${ }^{7}$ O comentário de Sara exemplifica: "Hoje em dia podemos sair e comprar memória na esquina, não é mesmo? Meus netos, pelo menos, já fizeram isso. Tomam um táxi e vão até a loja de computadores e compram memória [...]” (idem, p.118).
} 
leitura para este embate pode estar na noção de maior durabilidade da escrita, em oposição à fugacidade da palavra oral (GAGNEBIN, 2006, p.11) ${ }^{8}$. Optar exclusivamente pela palavra oral, como faz Gabriel pai, pode significar, em certa medida, a opção pelo esquecimento ${ }^{9}$. Na retórica oficial, nos elogios públicos e até mesmo no sermão de consolo do padre - que apura às pressas, com um bloquinho de repórter, informações sobre o defunto que enaltecerá -, as palavras faladas são copiosas e tantas vezes gratuitas no universo descrito por Vásquez.

Com seu trágico desenlace, a trajetória de Gabriel pai mostra o perdão como elemento indispensável, mas tantas vezes inatingível, para superar as desavenças do passado. Enquanto o suicídio de Konrad representa para ele o nascimento do sentimento de culpa essa experiência "fundamentalmente solitária", como definiu Ricoeur (2007, p.470) -, a operação cardíaca a que é submetido, décadas mais tarde, marca o início de sua busca por uma memória feliz, apaziguada e reconciliada, para seguir nos termos do filósofo francês. Bem-sucedida, a cirurgia lhe incute a crença na possibilidade de uma segunda vida, na qual os erros cometidos na juventude poderiam ser corrigidos. Reconcilia-se com Gabriel filho, permite-se lembrar com júbilo de experiências há muito soterradas e, após algumas semanas, decide empreender a última e crucial medida para se ver definitivamente livre do peso que o esmaga há décadas: pedir perdão a Enrique. Mas o amigo traído não está disposto à reconciliação: “Foi nesta mesma vida que tudo aconteceu, Gabriel, e você está querendo fingir que foi em outra diferente. Mas não, não é possível. Olhe, vou lhe dizer a verdade: prefiro que a gente deixe tudo como está."”(VÁSQUEZ, 2004, p.308).

Enrique finge ter esquecido certos fatos (idem, p. 299), mas não convence Gabriel filho, que aceita um convite para visitá-lo, tempos depois de o pai morrer num acidente de carro após o encontro frustrado com o ex-amigo. Sua relação com a memória situa-se num ponto intermediário entre o silêncio de Gabriel pai e o anseio de rememoração de Sara. Enquanto Gabriel mantém em segredo suas lembranças (além de Sara, contara-as apenas à mulher já falecida), Enrique divide as suas não apenas com a esposa, mas também com o filho Sergio,

\footnotetext{
${ }^{8}$ Faço uma menção deliberadamente superficial a um debate amplo e imemorial para a filosofia. Matizes, ressalvas e contextualizações são dadas, exemplarmente, pela própria Gagnebin na obra citada.

${ }^{9}$ Chama atenção que um mesmo episódio - o suicídio de Konrad e, especificamente, o ataque ordenado por Enrique determine tanto seu desejo de esquecimento coletivo como sua virtual impossibilidade de escrever. Após a mutilação, Gabriel pai tem de aprender a redigir com a mão esquerda, mas jamais o faz de maneira satisfatória: "[...] escrever era um atestado de sua invalidez, de seu defeito, de sua vergonha" (idem, p.24).
} 
a quem mostra documentos e dá os dois livros de Gabriel filho. O objetivo, segundo ele, é que Sergio o entenda, que intua como foram as coisas naquele período. "A gente quer que os outros vivam o que aconteceu há cinquenta anos. E como se faz isso? Deve ser impossível. Mas a gente tenta, inventa estratégias”, justifica Enrique (idem, p.297).

Um dos riscos da tarefa está na postura agressiva de Sergio, que transfere para Gabriel filho a mesma cólera que, ao ler seus livros e inteirar-se da traição, sentira por Gabriel pai. “A questão também é comigo, não é só com o meu pai”, vocifera o filho de Enrique, tão logo vê o jornalista assomar-se à porta de sua casa (idem, p.292). Gabriel filho, por sua vez, tampouco deixa de se considerar um herdeiro e observa a permanência, inelutável, dos episódios que separaram seus pais.

Era possível afirmar, em nosso caso, que o tempo se mexera? Que diferença fazia o momento exato em que o erro e a delação haviam ocorrido, o momento exato em que certa mão fora amputada? Os fatos estavam presentes; eram atuais, imediatos, viviam entre nós; os feitos de nossos pais nos acompanhavam. (...) (idem, p.293-294).

Enrique se mostra um zeloso colecionador de documentos, que guarda em fichários as cartas escritas por Konrad, as cartas que a mãe enviou pedindo ajuda a senadores e a notícia de jornal sobre a inclusão do pai na lista negra dos imigrantes do Eixo. Ao contrário de Sara, porém, ele descarta a possibilidade de divulgá-las.

Mas Gabriel Filho se apropria das cartas, assim como transformara em livro episódios da vida pessoal do pai. Cabe a ele, no romance, levar adiante o dever de memória ${ }^{10}$, vasculhando intimidades, garimpando documentos e - sobretudo - fixando no papel lembranças que, do contrário, não venceriam as interdições privadas e tenderiam a desaparecer com o passar do tempo. Na maioria das vezes, as testemunhas representam o único caminho possível para obter informações que - manipuladas ou reprimidas -

\footnotetext{
${ }^{10}$ Surgida nos anos 1990 e hoje um lugar-comum na França (Heymann, 2006), a expressão se refere essencialmente à necessidade de não esquecimento de crimes contra a Humanidade, como o Holocausto e as inúmeras outras atrocidades cometidas ao longo do século XX.
} 
desapareceram da esfera pública ou sequer foram transmitidas. Observando Sara ao lado de seu pai, Gabriel reflete sobre a experiência acumulada por aqueles dois "receptáculos de memória", e se angustia com a ameaça de esquecimento que sua futura morte representa (idem, p.85).

Eu recordava as palavras gravadas, erguia a cabeça para ver os outros comensais - minha família - e pensava isto que sempre é incrível: isso aconteceu com vocês. Isso, ocorrido há meio século, aconteceu com vocês, e aqui vocês estão, ainda vivos, funcionando como testemunho tangível de fatos e circunstâncias que talvez morram quando vocês morrerem, como se vocês fossem os últimos seres humanos capazes de executar uma dança andina que ninguém conhece, ou como se soubessem de cor a letra de uma música que nunca foi anotada e que se perderá para o mundo quando vocês a esquecerem (idem, p.85-86, grifo do autor).

Mas, embora sejam suas principais fontes, as testemunhas se mostram insuficientes, com suas frequentes omissões (deliberadas ou não), imprecisões, modificações e os contumazes acréscimos e desvios produzidos pela imaginação. Um primeiro revés para o jornalista vem de sua maior informante, Sara, que, nas entrevistas que concedeu para sua biografia, preferiu ocultar a presença de Gabriel pai entre os delatores das listas negras. O jornalista lamenta também que acontecimentos cruciais, como a delação feita pelo pai, sequer disponham de testemunhas, o que condena os interessados à angústia de tentar reconstituílos unicamente pela via imaginária. Favorecidas pela narrativa em primeira pessoa e pela estrutura metaficcional do relato, reflexões sobre a memória se multiplicam ao longo do romance e mostram que, para Vásquez, assim como para Beatriz Sarlo (2005), a valorização da memória não deve significar, de forma alguma, uma renúncia à discussão crítica sobre ela. Em diversos momentos, o narrador adverte o que há de escorregadio e traiçoeiro no ato de recordar. Por isso se ampara em documentos, confronta dados e se permite a possibilidade de corrigir as informações obtidas em depoimentos. 
Enquanto escrevo, verifico que no curso de vários meses acumularam-se sobre minha escrivaninha, mais do que as coisas e os papéis de que necessito para reconstruir a história, as coisas e os papéis que provam a existência da história e que podem corrigir minha memória caso seja necessário. Não sou cético por natureza, mas também não sou ingênuo, e sei muito bem a que magias baratas a memória pode recorrer sempre que lhe convém [...] (idem, p.94, grifo do autor).

Curiosamente, a ação de Los informantes termina em 1995, um ano antes da partida de Vásquez para a Europa - o que reforça, nos que atentarem a este detalhe, a crença no caráter pessoal de boa parte das impressões deixadas sobre o país ao longo da obra ${ }^{11}$. Referindo-se a uma cena de 1980, quando acabara de fazer 18 anos, Gabriel filho observa: "O tempo das bombas e dos atentados, uma década inteira em que vivemos com plena consciência de que voltar para casa à noite era questão de sorte, estava longe ainda" (VÁSQUEZ, 2004, p.20). Mais adiante, quando recebe de Sara a notícia do acidente do pai, o jornalista conta que "a escutava com uma certa distração e uma efêmera lástima altruísta, que é como costumamos escutar a notícia de uma morte alheia na Colômbia” (idem, 97).

Em seu ensaio sobre a condição de escritor deslocado ${ }^{12}$, Juan Gabriel Vásquez fez o seguinte comentário sobre Los informantes:

[...] quero pensar que todas as condições da minha experiência como inquilino - as incertezas, as particularidades de uma vida mais ou menos itinerante, a experiência fragmentada, a percepção, olhando de fora, de um país instável e, sobretudo, o tratamento desse país como território desconhecido - estão incluídas de maneira tácita no romance. (2009, p.188).

Não é preciso ler o ensaio para fazer essa constatação. Oito anos depois de sair da Colômbia, Vásquez fez do deslocamento não apenas um ingrediente fundamental da trama, mas uma postura discursiva para se pronunciar criticamente sobre seu país. Confirmando a

\footnotetext{
${ }^{11}$ Em seu romance mais recente, El ruido de las cosas al caer (2011), o protagonista é um jovem advogado atingido acidentalmente num ataque a um narcotraficante. Nas entrevistas de divulgação, Vásquez qualificou o livro como o seu mais autobiográfico, por tratar da insegurança que experimentou pessoalmente na Colômbia.

12 "Literatura de inquilinos", in El arte de la distorsión. Madri: Alfaguara, 2009.
} 
tese de Abril Trigo (2003) sobre o poder questionador da memória dos deslocados, o autor resgata um episódio mal acomodado na história oficial e ataca duramente os pilares do imaginário social colombiano. Seja a Colômbia dos anos 1940, em que imigrantes como Konrad, inicialmente acolhidos, são espoliados e vilipendiados pelo governo; seja a dos anos 1990, arrasada pela violência que mata o amante e os pais de outra personagem. O país em que o assassinato de um líder popular é respondido com crueza redobrada que se alastra por uma década. E onde até mesmo numa procissão religiosa uma mulher é marginalizada pelo fato de ser negra. Um lugar, em suma, versado em expulsões (VÁSQUEZ, 2004, p.276), pátria que se manifesta na morte e em situações dolorosas: nas cores do seguro de vida (idem, p.21), no hematoma do pai com as formas de uma província do norte (idem), na camisa que o narrador usa (Colombia nuestra), quando lhe contam que ficou órfão. Relatores do nazismo, da violência e da exclusão, os informantes do livro são testemunhas da experiência nacional fracassada. Dos desenganos de quem busca uma comunidade que extrapole os limites da imaginação.

\section{Referências}

AINSA, Fernando. "Palabras nómadas. La patria a la distancia y el imposible regreso". In: Letral, n.5, Granada, 2010.

ALTHUSSER, Louis. "Ideology and Ideological State Apparatuses". In: Lenin and Philosophy. Nova York: Monthly Review Press, 1971.

Montesquieu, Rousseau, Marx. Londres: Verso, 1972.

ANDERSON, Benedict. Comunidades imaginadas. Reflexões sobre a origem e a expansão do nacionalismo. São Paulo: Cia das Letras, 2008. 
BOLAÑOS, Aimée G. "Diáspora”. In: BERND, Zilá. Dicionário das mobilidades culturais; percursos americanos. Porto Alegre: Literalis, 2010.

CLIFFORD, James. Itinerários transculturales. Barcelona: Gedisa, 1999.

COLOMBI, Beatriz. Viaje intelectual. Migraciones y desplazamientos en América Latina (1880-1915). Rosário: Beatriz Viterbo, 2004.

CORRAL, Wilfredo (org.). "Las dos orillas: nueva literatura transatlántica" (dossiê). In: Quimera. Revista de Literatura, v. 245, Barcelona, 2004.

DE MAESENEER, Rita; VERVAEKE, Jasper. "Escribimos porque la realidad nos parece imperfecta". Entrevista com Juan Gabriel Vásquez. In CiberLetras: revista de crítica literaria y de cultura (Lehman College), n.23, julho de 2010.

DONOSO, José. Historia personal del boom. Barcelona: Anagrama, 1972.

FERMAN, Claudia. "Nuevas localidades para la producción cultural: diáspora, identidad y escritura". Comunicação realizada no congresso LASA 97, da Latin American Studies Association, em Guadalajara (México), 17 a 19 de abril de 1997.

FOMBONA, Jacinto. La Europa necesaria. Textos de viaje de la época modernista. Rosário: Beatriz Viterbo, 2005.

GAGNEBIN, Jeanne Marie. Lembrar, escrever, esquecer. São Paulo: Editora 34, 2009.

HALL, Stuart. Da Diáspora: identidades e mediações culturais. Org. Liv Sovik; trad. Adelaine La Guardia Resende. Belo Horizonte: Editora UFMG, 2003.

HARALD, Weinrich. Lete: arte e crítica do esquecimento. Rio de Janeiro: Civilização Brasileira, 2001. 
HEYMANN, Luciana. O "devoir de mémoire" na França contemporânea: entre a memória, história, legislação e direitos. Rio de Janeiro: CPDOC, 2006. 27f.

HOBSBAWN, Eric. Era dos extremos. O breve século XX: 1914-1991. São Paulo: Companhia das Letras, 1995.

HOLLANDA, Diogo de. "Romance do colombiano Gabriel Vasquez mostra vícios do continente". Rio de Janeiro: O Globo, suplemento Prosa \& Verso, 22/05/2010.

LE GOFF, Jacques. História e memória. Campinas: Unicamp, 2003.

MORAÑA, MABEL. Documentalismo y ficción: testimonio y narrativa testimonial hispanoamericana en el siglo XX. In PIZARRO, Ana (org.). América Latina. Palavra, Literatura e Cultura. Campinas: Editora da Unicamp, 1995.

NORA, Pierre (ed). Les lieux de mémoire. Paris: Gallimard, 1984.

PALMERO, Elena. "Deslocamento/desplaçamento”. In: BERND, Zilá. Dicionário das mobilidades culturais; percursos americanos. Porto Alegre: Literalis, 2010.

Memoria y representación del lugar en las escrituras desplazadas: espacios de la imaginación migrante en la literatura hispano-canadiense. In: Atas do JALLA 2010 Jornadas Andinas de Literatura Latino-Americana: América Latina, integração e interlocução. Niteroi: Universidade Federal Fluminense, 2010.

PAZ, Octavio. Los hijos del limo. Barcelona: Seix Barral, 1974.

. La búsqueda del presente (discurso proferido na cerimônia de aceitação do Prêmio Nobel), $1990 . \quad$ Disponível em: http://www.nobelprize.org/nobel_prizes/literature/laureates/1990/paz-lecture-s.html 
PIGLIA, Ricardo. Tres propuestas para el próximo milenio - y cinco dificultades. Buenos Aires: Fondo de Cultura Económica, 2001.

PIZARRO, Ana. El sur y los trópicos Ensayos de cultura latinoamericana. Cuadernos de América sin nombre, n.10. Alicante: Universidad de Alicante, 2004.

PRADA OROPEZA, Renato (org). El discurso-testimonio y otros ensayos. Cidade do México: UNAM, 2001.

RAMA, Ángel (ed). Más allá del boom: literatura y mercado. Buenos Aires: Folios Ediciones, 1984.

RICOEUR, Paul. A memória, a história, o esquecimento. Trad.Alain François [et al]. Campinas: Editora da Unicamp, 2007.

__. “O perdão pode curar?”. In: HENRIQUES, Fernanda (coord.). Paul Ricoeur e a simbólica do mal. Porto: Edições Afrontamento, 2005, p.35-40.

ROSMAN, Silvia. Dislocaciones culturales. Nación, sujeto y comunidad en América Latina. Rosário: Beatriz Viterbo, 2003.

SAFATLE, Vladimir. "Teoria da solidão impossível”. Entrevista com Paul Ricoeur. São Paulo: Folha de S. Paulo, 29/05/2005.

SALAZAR, Diego. Entrevista a Juan Gabriel Vásquez. ClubCultura.com (portal cultural da livraria Fnac). Disponível em http://www.clubcultura.com/clubliteratura/jgvasquez/. Acessado em 18/01/2012, às 16h05.

SARLO, Beatriz. Tiempo pasado: cultura de la memoria y giro subjetivo. Una discusión. Buenos Aires: Siglo XXI, 2005. 
SELIGMANN-SILVA, Márcio. História, memória, literatura: o testemunho na Era das Catástrofes. Campinas: Editora da Unicamp, 2003.

SOMMER, Doris. Ficções de fundação: os romances nacionais da América Latina. Belo Horizonte: Editora da UFMG, 2004.

STEINER, George. Extraterritorial: a literatura e a revolução da linguagem. São Paulo: Companhia das Letras, 1990.

TODOROV, Tzvetan. Los abusos de la memoria. Barcelona: Paidós, 2000.

TRIGO, Abril. Memorias migrantes. Testimonios y ensayos sobre la diáspora uruguaya. Rosário: Beatriz Viterbo, 2003.

VARGAS LLOSA, Mario. Sables y utopias: visiones de América Latina (textos selecionados por Carlos Granés). Buenos Aires: Aguilar, Altea, Taurus, Alfaguara, 2009.

VÁSQUEZ, Juan Gabriel. Los informantes. Madri: Alfaguara, 2004.

. Os informantes. Trad. Heloisa Jahn. Porto Alegre: L\&PM, 2010.

.. Historia secreta de Costaguana. Madri: Alfaguara, 2007.

.. El ruido de las cosas al caer. Madri: Alfaguara, 2011.

. "Literatura de inquilinos". In: El arte de la distorsión. Madri: Alfaguara, 2009, p. 179-189.

VÉLIZ, Miriam. "La novela es uma atalaya contra el olvido”. Entrevista com Juan Gabriel Vásquez. San Juan: Hoy Digital, 25/11/2011. 
VIGLIONE, Daniel. "Irme de Colombia me ayudó para ser escritor". Entrevista a Juan Gabriel Vásquez. El observador, Montevidéu, 02/04/2011.

VOLPI, Jorge. "América Latina, holograma". In: El insomnio de Bolívar. Cuatro consideraciones intempestivas sobre América Latina en el siglo XXI. Buenos Aires: Debate, 2009. 